\title{
Wildlife Trends in Liberia and Sierra Leone
}

\section{P.T. Robinson}

In an eight-month field study of the pygmy hippopotamus, an endangered $\operatorname{Red}$ Book species, the author was able to make some assessment of the status of other animals in Liberia and Sierra Leone and shows how the danger is increasing for most of them. Chimpanzees in particular are exported in large numbers, and in order to catch the young animals whole family groups may be eliminated.

West African countries have made little effort to conserve their unique types of vegetation and wildlife. Instead the tendency has been to establish parks and reserves in grassland areas that are similar to those of East Africa. But Sierra Leone, Liberia and the Ivory Coast all have areas of mature tropical rain forests where reserves could be established. The high forests of the tropics are of great value, culturally, scientifically and economically, and it is important to conserve their unique types of fauna and flora.

\section{Rare and Uncommon Species}

The pygmy hippopotamus Choeropsis liberiensis is one of West Africa's unique species, dependent on forest vegetation, which is decreasing seriously. Nowhere is it abundant in the four countries where it occurs: Sierra Leone, Guinea, Liberia and Ivory Coast. Comparisons with its past distribution show that populations today are much more localised; for example, the disrupted distribution pattern across Liberia is related to the major motor-road arteries, which form avenues of human settlement. Increased population, hunting, agriculture, forestry and mining, combined with the hippo's non-gregarious nature, low reproductive rate and apparent susceptibility to hunting and adverse land use, have resulted in a steady decrease in its range. If the wild populations are to survive it will have to be in protected areas where essential habitats are preserved and other disturbance regulated; its survival in captivity seems assured. A more detailed account of its status will be available soon.

Jentink's duiker Cephalophus jentinki, which has the most restricted range of all existing Cephalophinae, is another unique West African species, found only in eastern Liberia and the western Ivory Coast, where its distribution is centred on the Cavally River (Kuhn, 1965). It inhabits mainly undisturbed forests, and even in the heart of its range is not abundant. In eastern Liberia I saw skins and skeletal parts of this duiker killed by hunters. Recent efforts by dealers to obtain live specimens for export succeeded in Liberia, and in 1968-69 the Omaha Zoo in Nebraska, USA, bought three animals, two females and a male. Sold again recently, they have been moved to Brownsville, Texas, where it is hoped to establish a breeding colony.

The banded or zebra duiker $C$. zebra has a greater range and is commoner than Jentink's duiker, although it is regularly hunted for its 
meat and attractive hide. I saw one live pair in the Grebo Forest in Liberia in the dry season of 1968 , and a hunter from west of the Cestos River, who had gone out to bag monkeys for food, returned with an adult zebra duiker as well. In Sierra Leone skins were to be seen in the Gola Forest in the east. Sierra Leone now prohibits the export of zebra duikers.

The bongo Boocercus eurycerus is restricted to forest areas, and although I visited numerous wooded localities where it was described as being formerly present, I saw none. In some parts bongo horns are traditionally used to sound a summons to villagers. Bongo are occasionally shot by local hunters, even though they are wary and difficult to approach.

All the signs are that chimpanzees are decreasing in most of the parts of their range that I visited; interviews in the field confirmed this. Between 1957 and 1968, at least 2574 chimpanzees were exported from Sierra Leone alone, according to data from the government Wildlife Branch. From Liberia, where accurate data were not available, incomplete export records indicated that at least 570 chimps were shipped out of that country between 1958 and 1968. To produce that quantity of exportable animals natural populations may have been reduced by three times that number because of the usual tremendous wastage of both mothers and young. According to dealers, most of the animals exported are the young. Hunters told me that the method of capture is to set nets and snares in a cleared strip of forest into which the chimps are driven by large hunting parties. Unmanageable adults are usually killed on the site so that whole family groups may be eliminated. I have not been able to make any estimate of the size of the populations in these two countries. The export quotas set by the Forestry Division in Sierra Leone are evidently not based on knowledge of field populations or of capture results. Liberia has no guidelines, either, for determining what volume of animal exports may reasonably be allowed. Except for capturing the young, chimpanzees are not intensively hunted where they are not damaging to agriculture, but the overseas demand for chimps as research animals is considerable.

Leopards are seldom seen now in Sierra Leone. At the beginning of the century leopard damage was frequently recorded by colonial officers in the north, and in some localities leopards were thought to be preventing any increase in cattle numbers (Probyn, 1905). Evidently the use of firearms in recent years has diminished their numbers considerably. In Liberia I saw tracks and also skins, but the price of skins has risen to US $\$ 20-\$ 75$, and apparently continues to increase as they become scarcer. Such prices are a big incentive to over-hunting.

The manatee Trichechus senegalensis is still found in some large river estuaries in Sierra Leone and Liberia; in Greenville, Liberia, fishermen told me that they also occasionally see them in large estuaries. The University of Liberia had a plaster cast of a manatee, caught near the mouth of the St. Paul River in 1966. The exact status of this species is not known, but they were reported to be occasionally taken by harpoon and gun.

The bald crow or grey-necked rockfowl Picathartes gymnocephalus is found in both Liberia and Sierra Leone, but is not common; it 


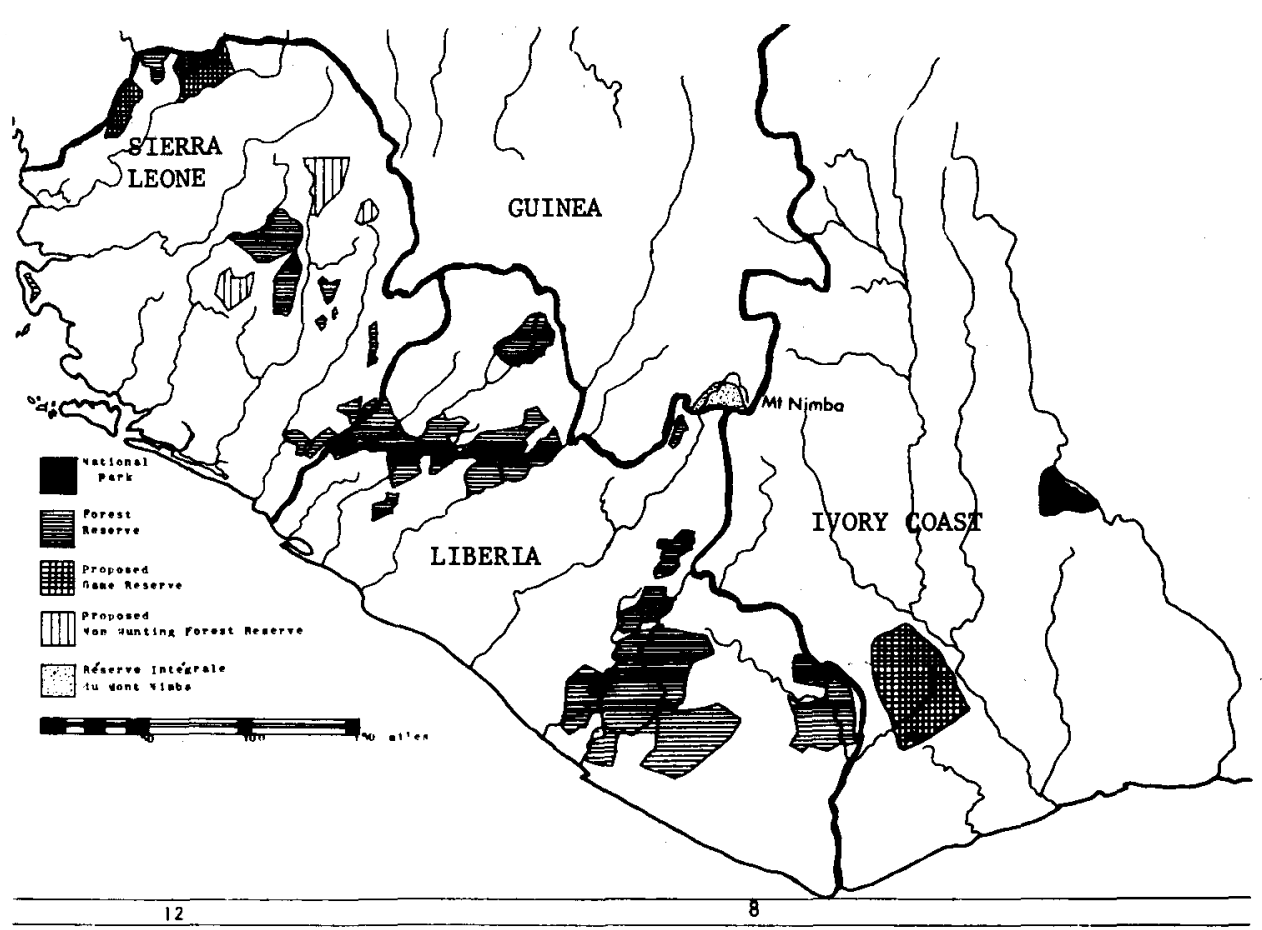

inhabits certain secluded forest areas where rocky ledges and steep rock outcrops serve as nest sites, and its colonial nesting habits make it very susceptible to hunting. Sierra Leone bans all exports, but Liberia exports live specimens without restriction. In at least one locality in Liberia, all the birds in one colony were killed by villagers after animal collectors had disturbed it. The status of wild populations is uncertain at best. One European dealer is reputed to have reared them successfully in captivity.

\section{Animals Formerly Present}

Although as long ago as 1905 the lion had disappeared from Sierra Leone, according to Major Fairtlough's reports in the Sierra Leone Archives (1905), int recent years there have been several isolated reports of lions in the north. The most recent was an adult female seen south of Kabala in 1959 by a missionary, Paul Dekker (1968, in conversation). The missionaries also told me that lions may still be found in a number of localities in Guinea, Sierra Leone's northern neighbour; they have never been reported in Liberia. The Derby eland Taurotragus derbianus is no longer to be found. About 1900 it ventured occasionally into Koinadugu District, in northern Sierra Leone, but Major Fairtlough (1905) considered these to be uncommon intrusions from populations centred closer to Futa Jallon and Futa Toro in Guinea.

\section{Common Large Animals}

Elephants are still found in the more remote parts of both Liberian and Sierra Leone forests, and also in northern Sierra Leone where they used to cause damage and are not uncommonly hunted. The available 
firearms, however, are almost always inadequate to kill an elephant safely or efficiently. At least in Liberia, the usual method is to fire an iron-tipped wooden shaft from a twelve-gauge shotgun at very close range. This is not always fatal and sometimes the hunter is killed by the elephant or even by the explosion of his firearm.

The only report of the common hippo in Liberia is based on plaster casts of tracks found in 1962 by Mr. Harry Gillmore along the St. Paul River near the Guinea border (in conversation, 1968). Johnston (1905) found no evidence of it. In Sierra Leone the Great Scarcies, Little Scarcies and Kaba rivers are the only localities in the two countries where it appeared to be present in 1968. Tracks and grazing signs were found in several of these localities, and one specimen was sighted in the Little Scarcies. Though occasionally hunted, in most areas they are left undisturbed because of the lack of adequate firearms.

The West African buffalo or bushcow is occasionally present in the rain forests but is more typical of savanna vegetation in northern Sierra Leone, where it is common in many areas. Several missionaries in Sierra Leone, with considerable hunting experience, reported noticeable decreases over the past twenty years in the group sizes; where formerly herds of $25-40$ wculd be seen, more recently they have numbered only 5-12 animals. Waterbuck Kobus defassa, which are found in many localities in northern Sierra Leone, are reported to show similar decreases. According to missionary David Rupp of Magburaka, kob Adenota $k o b$ are present only in several areas of Tonkolili, Bombali and Kambia Districts (in conversation, 1968). The harnessed antelope or bushbuck Tragelaphus scriptus is still fairly common throughout the forest-mosaic and savanna zones of Sierra Leone.

Other Cephalophinae found in the areas visited include seven duikers: the yellowback Cephalophus sylvicultrix, black $C$. niger, black-backed $C$. dorsalis, red-flanked $C$. rufilatus, Ogilby's $C$. ogilbyi, gray Philantomba maxwelli, and crowned Sylviacapra grimmia. The royal antelope Neotragus pygmaeus is common in many areas of farm bush and also in the northern savanna. No tangible evidence of the water chevrotain Hyemoschus aquaticus was found in Sierra Leone, but its tracks were seen in various localities in Liberia and one fresh carcase was examined west of Bomi Hills in 1968.

Skeletal remains and dens of the aardvark Orycteropus ater were observed in north-western Sierra Leone. The spotted hyaena Crocuta crocuta, while not common, is also present in northern Sierra Leone, according to a forestry official in Makeni, who showed me a dried skin. The forest hog Hylochoerus meinertzhageni and red river hog Potamochoerus porcus are common additions to hunters' bags in forested areas, and the warthog is in northern Sierra Leone.

In many of Sierra Leone's forested areas three coloboid monkeys Colobus polykomos, $C$. badius and $C$. verus are found, but are not reported by cultivators to be damaging to agriculture, as are all other monkeys, except for Diana's guenon Cercopithecus diana, when they occur in large numbers. In descending order of destructiveness, according to T.S. Jones (1951), they are: Cercocebus torquatus, Cercopithecus mona, $C$. nicitans and $C$. aethiops. Monkeys are especially destructive to cacao, while baboons Papio papio and red 
patas monkeys Erythrocebus patas create problems on the ground-nut farms of northern Sierra Leone.

Monkeys are widespread throughout Sierra Leone and particularly abundant in the eastern and southern provinces, despite post-war drives to reduce populations in which, between 1948 and 1950 alone, head bounties were paid for over 60,000 monkeys (Jones, op.cit.). The Moslem practice of not eating monkey flesh has favoured their survival in some areas. In Liberia monkeys are much more heavily persecuted and are seldom seen except in remote areas. Liberian commercial hunters have recently developed a trade in dried monkeys; in eastern Sierra Leone they shoot the animals and sell them in Liberian mining camps and Monrovia markets. No volume estimate of this trade, which is not confined to monkeys, has been made. One group of men was seen with dried monkeys bundled into head loads along with a fresh banded-duiker hide. Local residents reported that groups of chimpanzees also have been killed by Liberian monkey-hunting parties.

\section{Prospects for Wildlife Management}

Officials in both Liberia and Sierra Leone are receptive to the idea of expanding their activities in managing wildlife, but discouraged by the lack of trained personnel to staff such a programme effectively and the inadequate government budgets. Hopefully, additional wildlife studies sponsored by conservation organisations will catalyse an increasing awareness of wildlife and national park problems and potentialities among national budget planners. The spirit of helpfulness with which this project was received should encourage other investigators to contribute to a better understanding of animal populations in West African countries.

\section{Acknowledgments}

The field survey, from January to July 1968, was initiated by Professor George A. Petrides, of Michigan State University, who assisted in the early stages, and was supported by the World Wildlife Fund. The survey was greatly helped by Mr. J.S. Sawyer, Chief of the Forestry Division in Sierra Leone, who has recently established a Wildlife Branch, headed by Mr. Donald Elliot, a graduate of the College of African Wildlife Management at Mweka, Tanzania, and by Mr. Anthony Sayeh, head of the Bureau of Forest Conservation, which is responsible for wildlife in Liberia; Mr. Dak Tooba, forest surveyor in Liberia, provided invaluable field assistance. They and their staffs greatly facilited the survey and their helpfulness is hereby gratefully acknowledged. Dr. Petrides kindly reviewed this report.

\section{Literature Cited}

BỦTTIKOFER, J. 1890. Reisebilder aus Liberia. 2 vols. Leiden.

FAIRTLOUGH D.S.O., MAJOR. 1905. An amended list of animals found in the Protectorate of Sierra Leone. Sierra Leone National Archives. 1538/1905. Freetown, Sierra Leone.

JOHNSTON, H. H. 1905. Notes on the mammals and birds of Liberia. Proc. Zool. Soc. Lond. 1: 197-210.

JONES, T. S. 1951. Notes on the monkeys of Sierra Leone. S.L. Agricultural Notes. No. 22. GPO Freetown. 
KUHN, H. J. 1965. A provisional checklist of the mammals of Liberia. Senckenbergiana Biologica. 46(5): 321-340.

PROBYN, L. 1905. Untitled paper. 1538/195/1905. Sierra Leone National Archives. Freetown, Sierra Leone.

ROBINSON, P. T. 1969. Pygmy hippopotamus - ecological study in West Africa. Project No. 204. World Wild Life Fund Yearbook 1968. 123-125.

ROBINSON, P. T. 1970. The status of the pygmy hippopotamus and other wildlife in West Africa. M.S. Thesis. Dept. of Fisheries and Wildlife. Michigan State University. E. Lansing, Michigan. USA. 80pp.

The author is associated with the US Department of Fisheries and Wildlife. His present address is the College of Veterinary Medicine, Michigan State University, East Lansing, Michigan, USA.

\section{New Regulations in Ghana}

Under the new Wildlife Conservation Regulations, which came into force in Ghana in April this year, complete protection is given to chimpanzee, leopard, pangolin, three species of crocodile, hawksbill, green and leatherback turtles, bare-headed rockfowl Picathartes and all birds of prey and owls. Many other animals, including all parrots, get partial protection. The regulations also mark a great advance in the control of exports. Whereas before there was no legal control of the capture or export of wild animals unless the actual killing of a protected animal could be proved (except in the case of the African grey parrot Psittacus erithacus), now capture as well as killing of protected species is illegal. Game licences are to be issued by the Game and Wildlife Department, and trade in wildlife and wildlife products will be closely controlled. Perhaps most important of all is the news that police and customs authorities are co-operating in the enforcement of the new regulations.

\section{Plans for a Ghana Reserve}

Ghana's Shai Hills Game Reserve near Accra is to be fenced and turned into a multi-purpose reserve - for wildlife, tourism, education, recreation and research. It will be re-stocked with the original fauna of the Accra Plains, and provided with nature trails, a laboratory/lecture room, and other facilities. The Game and Wildlife Department will continue research into the market for bushmeat, and also on some of the animals involved, particularly the grasscutter (the cane rat Thryonomys swinderianus), the reserve's carrying capacity, and possible take-off rates.

\section{Ivory Coast Reserve Plans}

West Africa urgently needs wildlife reserves and national parks to protect its tropical forest, as the author of the article on page 117 points out. Such an area is the Tai Forest Reserve in the south-west Ivory Coast, which IUCN, supported by WWF, is now surveying preparatory to drawing up a management plan, after discussions with the Ivory Coast government. With a rich fauna and flora that includes several Red Data Book mammals, it is described as 'the last undisturbed lowland tropical rain forest in Africa west of the Dahomey gap', and it is under considerable pressure from timber companies that have even built mills close to the reserve in expectation of securing concessions. 


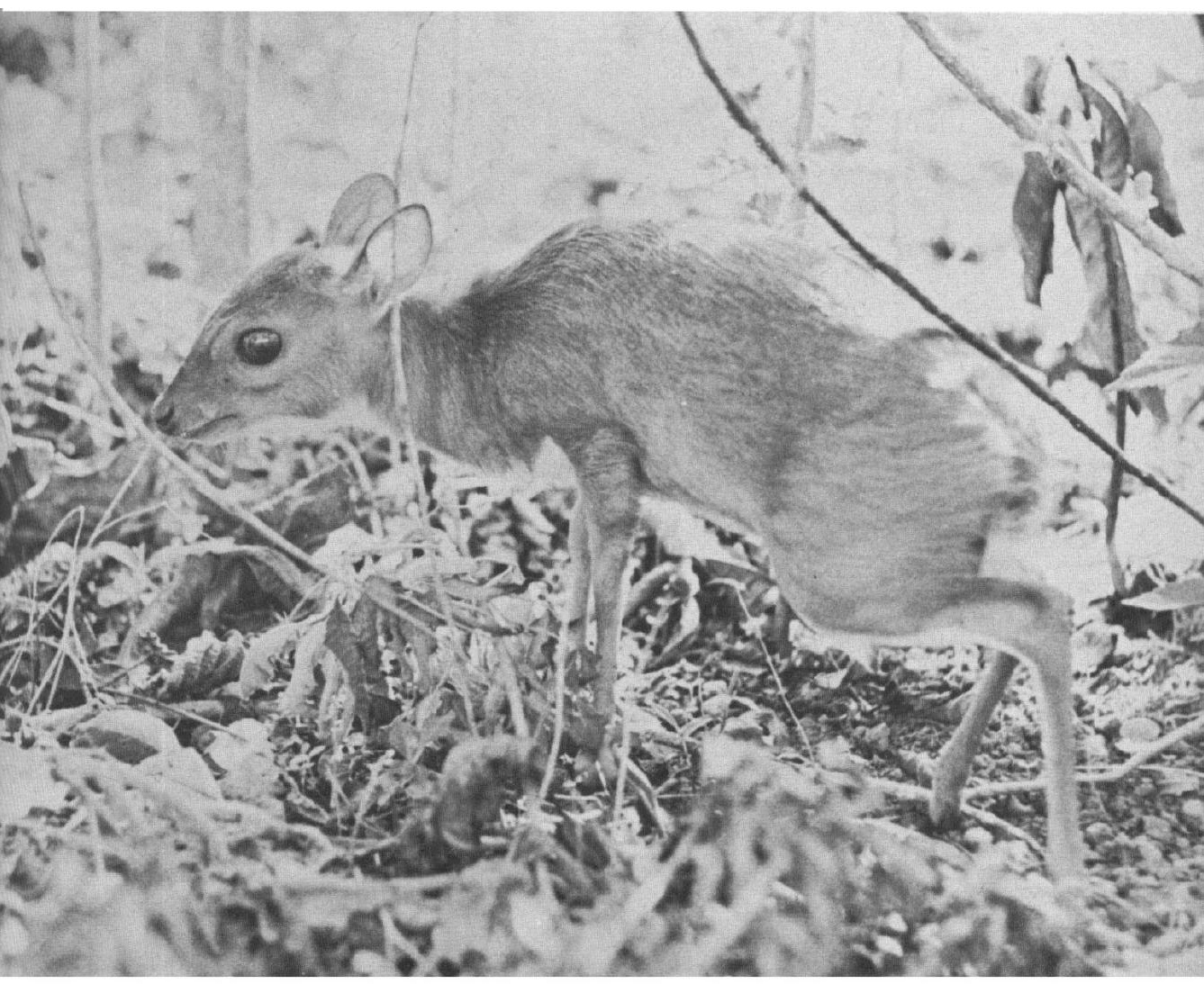

ROYAL ANTELOPE. The smallest antelope in the world, the royal, or pygmy, antelope Neotragus pygmaeus lives in the tropical forests of West Africa, from Sierra Leone to the Cameroons. Not more than 10-12 ins. high at the shoulder this one was only $7 \frac{1}{2}$ ins - it is nocturnal and rarely seen, and little is known about the species. This captive animal was brought to the Fourah Bay College Zoology Department, in Freetown, Sierra Leone, and Mrs Jennifer Owen, who sent us the photograph, writes: Its coat is a warm, golden brown with white chin and underparts and a fluffy white tail. The hoofs are tiny and pointed, and it cannot stand on a smooth surface. There is no sigh of horns, but facial glands appeared two months ago. Nervous and alert, it seems all large brown eyes, delicate mobile ears and twitching nose. The long hindlegs, normally held bent with the 'ankle' joints tucked under the tail, enable it to leap and bound when running. 


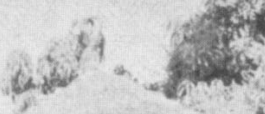

is
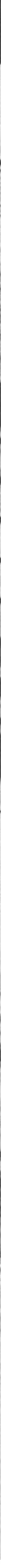

ABUKO NATURE RESERVE. Top the rest house in The Gambia's first nature reserve, described in Oryx, September 1970, by Sir Landsborough Thomson. Below the heavy chain-link fencing that was essential to preserve this small reserve and which was supplied by the FPS/WWF Revolving

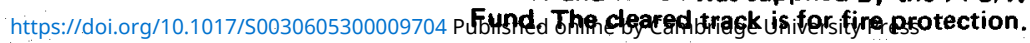




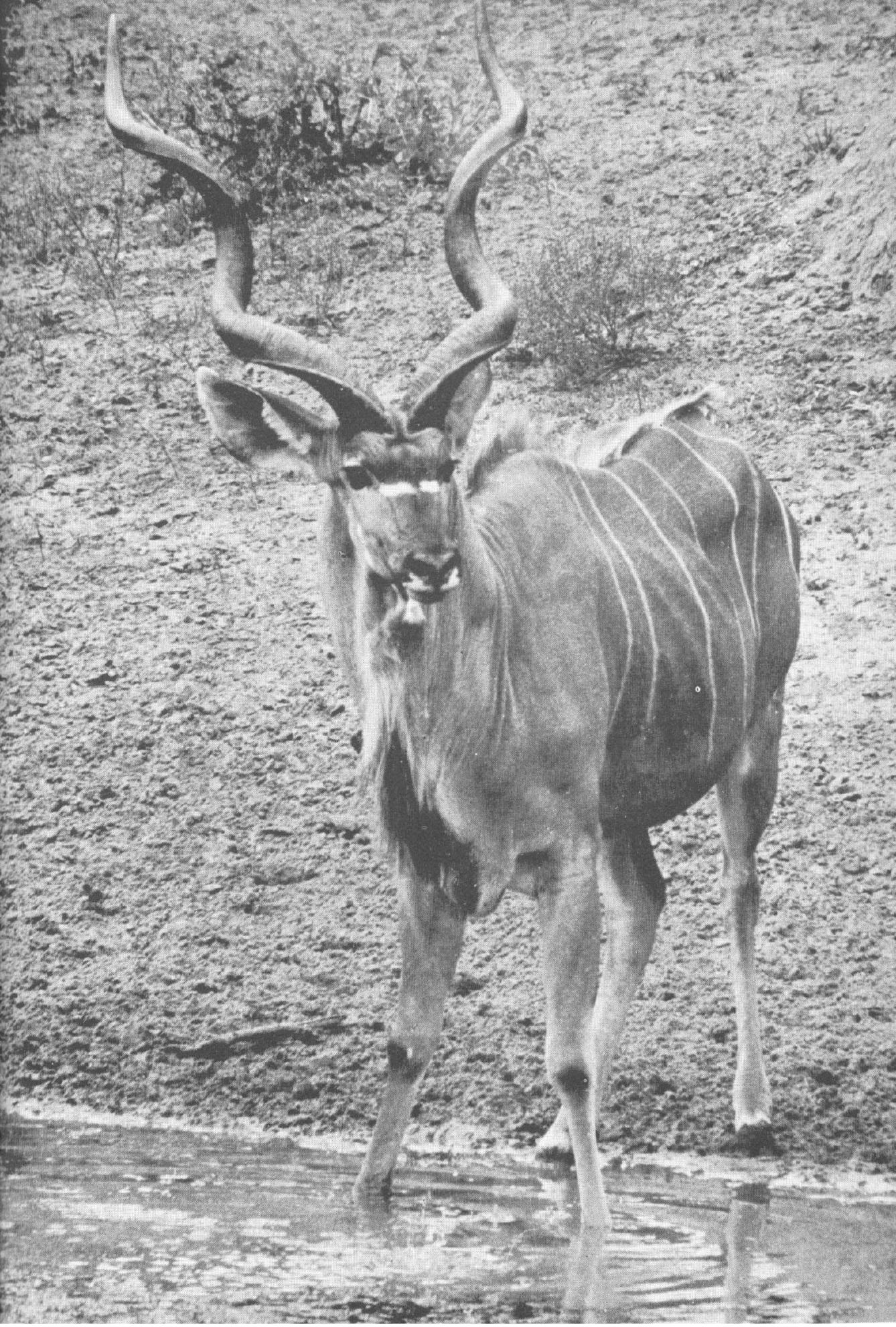




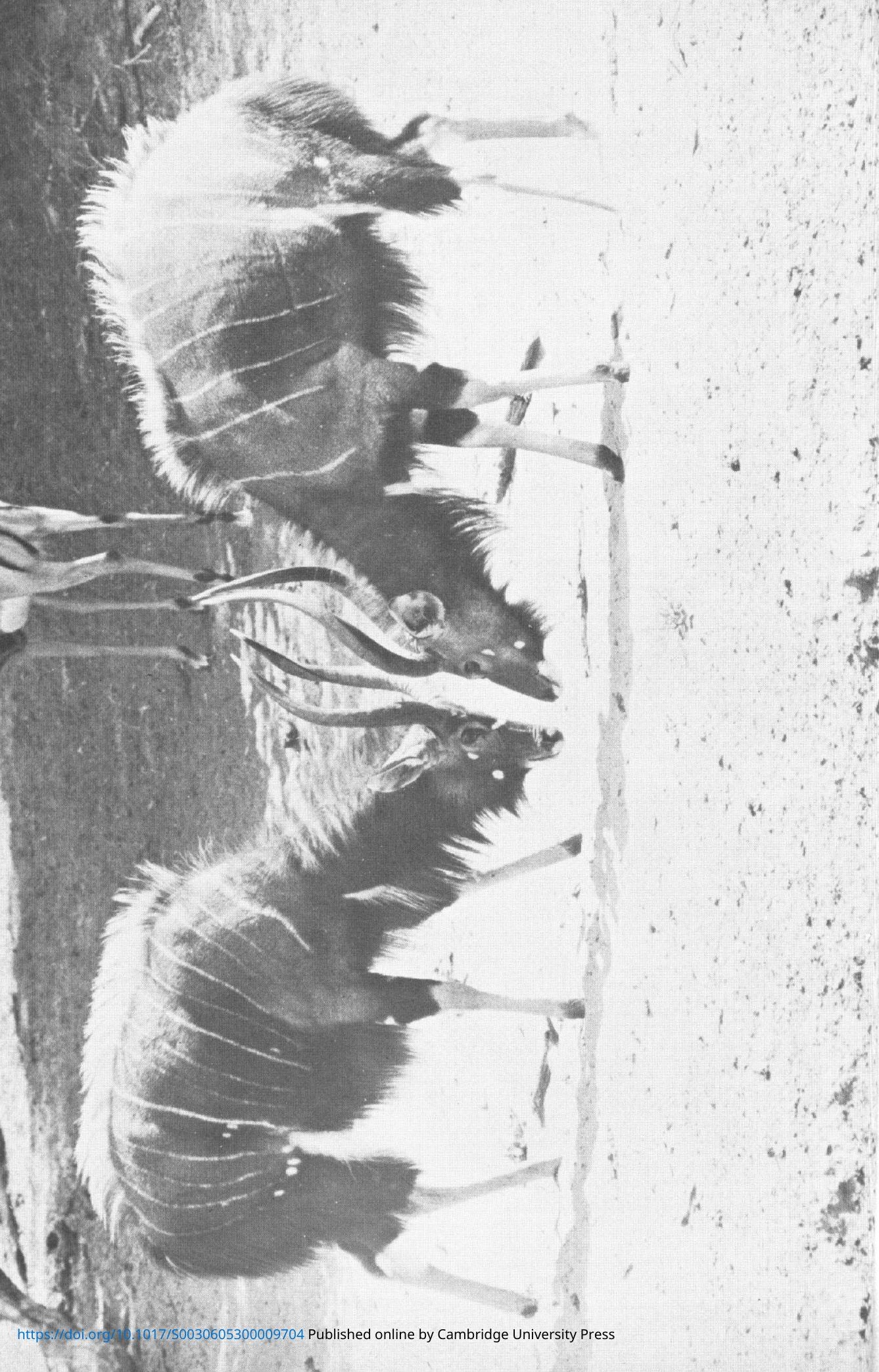


